\title{
Modelling long-wave radiation heat exchange for thermal network building simulations at urban scale using Modelica
}

\author{
Moritz Lauster, Peter Remmen, Marcus Fuchs, Jens Teichmann, Rita Streblow, Dirk Müller \\ RWTH Aachen University, E.ON Energy Research Center, Institute for Energy Efficient Buildings \\ and Indoor Climate \\ Mathieustr. 10, 52074 Aachen, Germany \\ mlauster@eonerc.rwth-aachen.de
}

\begin{abstract}
There are different options for modelling indoor and outdoor long-wave radiation exchange in thermal building models for simulations at urban scale. For improving these building models, a good trade-off between accuracy and simulation time is a major challenge. To evaluate different radiation models for thermal network building models, we compared four outdoor radiation and two indoor radiation models.

For the comparison, we set-up three test cases on a generic room and a single family dwelling and analysed surface temperatures, heat demands, and simulation times. The results favoured an outdoor radiation exchange model according to the German Guideline VDI 6007 with modified parameter calculations. It includes important simplifications that lead to short computing time while keeping a sufficient accuracy. For indoor radiation exchange modelling at constant temperatures, a linear approach significantly reduces simulation time without any major accuracy losses.
\end{abstract}

Keywords: thermal network building model, equivalent outdoor temperature, long-wave radiation exchange, building performance simulation

\section{Introduction}

One current challenge in the field of building simulation is the thermal simulation of entire city districts. For this task, simplified building models are an interesting approach as they require comparably low parameterization and computational efforts. A comprehensive discussion of this topic can be found in $[1,2]$, which summarize the state-of-the-art in dynamic building simulation. The approaches to simplify building models include thermal network models, which are based on analogies to electrical problems and have successfully been applied at urban scale [3, 4].
Thermal simulation at urban scale aims at understanding and efficiently directing energy flows between different subsystems like generation units and buildings. Of particular interest are holistic control strategies and heat storage effects, because they offer potential for improving the energy system without the need for high investment. To investigate such measures, dynamic simulations at variable time step seem more promising than static and quasi-static calculations. Nevertheless, traditional building simulation environments are often limited to an hourly time step. Thus, a growing community is developing model libraries to simulate building performance at building and urban scale using Modelica [5, 6, 7, 8], often using thermal network models to describe thermal building behaviour.

Within common thermal network models, the longwave radiation heat fluxes on wall surfaces can be considered on different levels of detail. These heat fluxes are the result of temperature differences caused by indoor and outdoor sources such as heating systems and solar radiation. Different approaches exist for the calculation of radiative heat exchange. Some models use Stefan-Boltzmann law while others use linearized radiation equations. Thus, these models differ in the accuracy of their results as well as in computation time. So far, it has not been determined which of these models is best suited for thermal simulation at urban scale.

In this paper, we present four approaches to consider long-wave radiation exchange in building simulation. The aim is to evaluate these approaches regarding their suitability for thermal network building models and urban-scale applications by means of a balanced trade-off between physical resolution and calculation time [9].

Firstly, we present the methodology and modelling assumptions. Afterwards, we implement four models and define a benchmark test case. Finally, we discuss the simulation results and end with conclusions. 


\section{Modelling approaches}

\subsection{Building model validation}

Thermal network models describe heat transfer and storage problems with a number of thermal resistances and capacitances. While highly discretized models provide high spatial resolution, low order models require less computational effort at the cost of accuracy.

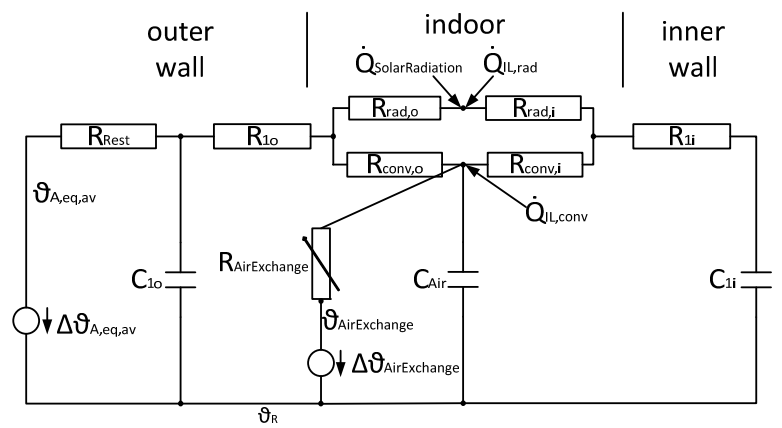

Figure 1: Low order building model derived from VDI 6007

In this study, we use a building model based on the German Guideline VDI 6007 [10] as seen in Figure 1. The model divides the building mass into two capacitances representing all internal and external building elements respectively. The heat transfer through the outer wall is described by two resistances while another resistance is used to damp the adiabatic inner wall capacity. The indoor heat exchange between the walls and the air node can be calculated in different ways. While the VDI 6007 defines a combined coefficient of heat transfer, we distinguish between radiative and convective heat transfer (Figure 1). Outdoor radiation sources like solar radiation are considered via an adapted equivalent outdoor air temperature $\vartheta_{\mathrm{A} \text {,eq,av }}$ (in the following referred to as $\mathrm{T}_{\mathrm{eq}}$ ). Substituting the outdoor air temperature with this equivalent outdoor air temperature is a way to incorporate the effects of long-wave radiation into the model.

While we kept most parts of the theory and model description given in VDI 6007, we did not follow the given analytical equations [11]. We rather took advantage of Modelica's abilities to formulate acausal equations in an object-oriented structure. We defined a sub-model for each element in Figure 1 and connected them to the circuit shown in Figure 6. Each sub-model describes either heat transfer phenomena (resistance) or storage effects (capacity)

In order to validate this thermal network model, we performed benchmark tests according to the American Standard ASHRAE 140 [12]. This standard provides a set of test cases and corresponding results of standard building models. If deviations in the validation process exceed given limits, the standard suggests further test procedures for each test case. In this way, the standard supports the identification of sub-models with optimisation potential. The tests gave valid results for most test cases. Nevertheless, the validation process identified problems with the handling of radiation exchange. One way to address this issue would be more detailed radiation exchange models, while potential simplifications should still be considered. Otherwise, radiation and building model could be out of balance by means of level of detail and required computational costs.

We identified long-wave radiation exchange as one key part for optimization. It seems to have major influence on heat demand [13] and different modelling approaches are available. As the ASHRAE provides no test case solely for the effects of long-wave radiation heat exchange, we refined one ASHRAE in-depth test set-up to focus only on long-wave radiation.

In the following sections, we will discuss and compare different approaches for outdoor as well as indoor long-wave radiation heat exchange.

\subsection{Outdoor long-wave radiation exchange}

According to VDI 6007, the heat flux due to ambient radiation sources on the outer walls can be considered in an equivalent adapted outdoor temperature.

Figure 2 shows typical influences that need to be considered in the adapted outdoor temperature. Radiation can be divided into short-wave and longwave. In contrast to short-wave radiation, measurement data of long-wave radiation sources are rarely available. Furthermore, long-wave radiation has to be subdivided into atmospheric, ambient and partly reflected ground radiation. Thus, empirical methods are used to consider the long-wave heat flow as a function of outdoor temperature and cloud coverage $[14,15,2]$.

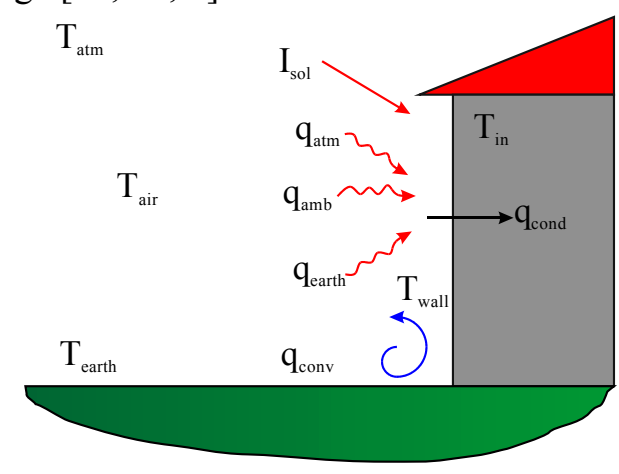

Figure 2: Heat flows on the outer wall 
According to Figure 2 a heat balance of the wall consists of:

$q_{\text {cond }}=q_{\text {short-wave }}+q_{\text {long-wave }}+q_{\text {conv }}$

Starting from this heat balance it is possible to implement models with different levels of simplifications (see Figure 3).

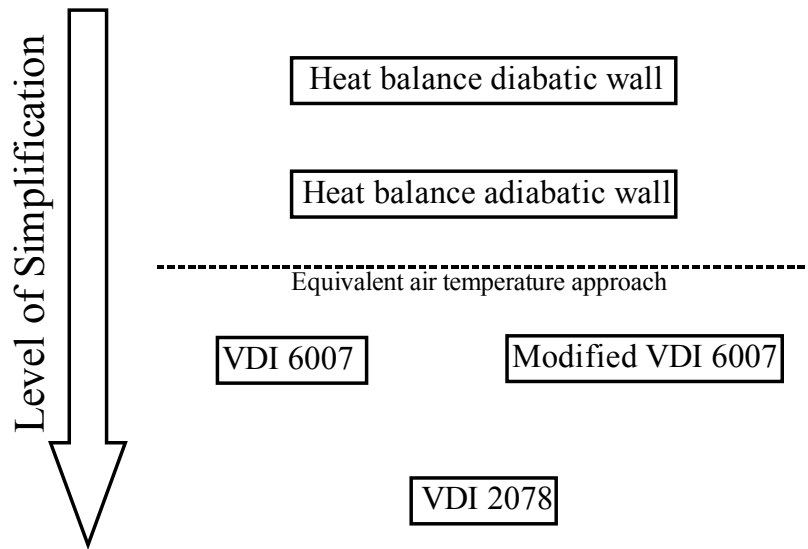

Figure 3: Schematic diagram of investigated models and their level of simplification

As a first simplification the outside wall can be considered as adiabatic, which leads to $\mathrm{q}_{\mathrm{cond}}=0$. In the following subsections we describe four ways to model long-wave radiation heat exchange. The meaning of the variables can be found in the nomenclature.

\subsubsection{Heat Balance}

The three occurring heat flows can be written as:

$q_{\text {conv }}=\alpha_{\text {conv }} \cdot\left(T_{\text {air }}-T_{\text {wall }}\right)$

$q_{\text {long-wave }}=\sigma \cdot \varepsilon_{\text {wall }} \cdot\left(\varphi_{\text {atm }} \cdot\left(T_{\text {atm }}^{4}-T_{\text {wall }}^{4}\right)+\right.$

$\left.\varphi_{\text {earth }} \cdot\left(T_{\text {earth }}^{4} T_{\text {wall }}^{4}\right)+\varphi_{\text {amb }} \cdot\left(T_{\text {air }}^{4} T_{\text {wall }}^{4}\right)\right)$

$q_{\text {short-wave }}=a_{a b s} \cdot I_{\text {sol }}$

$\varphi_{\mathrm{i}}$ is a view factor between the wall and considered long-wave radiation source. The temperature of extra-terrestrial sources, also called sky temperature, can be calculated as a function of long-wave radiation heat flux. Furthermore, the earth temperature can be regarded as equivalent to the outdoor air temperature $[16,17]$ :

$T_{\text {atm }}=\left(\frac{E_{\text {atm }}}{\sigma}\right)^{0,25}$
$T_{\text {earth }}=T_{\text {air }}$

Inserting Equations $2 \mathrm{a}-\mathrm{c}$ and $3 \mathrm{a} / \mathrm{b}$ in Equation 1 provides the heat balance of the adiabatic outside wall. This heat balance can be iteratively solved for $\mathrm{T}_{\text {wall. }}$. Without any further simplifications, this Heat Balance method provides a relatively detailed model.

\subsubsection{Equivalent air temperature according to VDI} 6007

A widely used simplification is to describe the occurring heat flows with one equivalent heat flux $[10,18,19]$. Introducing a combined radiative and convective coefficient of heat transfer and an equivalent temperature leads to:

$$
\begin{aligned}
& \alpha_{\text {comb }} \cdot\left(T_{e q^{-}}-T_{\text {wall }}\right)= \\
& q_{\text {short-wave }}+q_{\text {long-wave }}+q_{\text {conv }}
\end{aligned}
$$

Expressing the equivalent temperature according to VDI 6007 requires further assumptions. The longwave radiation heat exchange is linearized using $T_{\text {atm }}$ and $T_{\text {earth }}$, the wall temperature is set equal to the outdoor air temperature and $\mathrm{T}_{\text {atm }}$ and $\mathrm{T}_{\text {earth }}$ are calculated from long-wave radiation heat flows.

$$
\begin{aligned}
& T_{\text {atm }}=\left(\frac{E_{\text {atm }}}{\varepsilon_{\text {earth }} \cdot \sigma}\right)^{0,25} \\
& T_{\text {earth }}=\left(\frac{E_{\text {earth }}}{\varepsilon_{\text {earth }} \cdot \sigma}\right)^{0,25} \\
& \alpha_{\text {rad }}=\frac{T_{\text {atm }}^{4}-T_{\text {atm }}^{4}}{\left(T_{\text {atm }}-T_{\text {earth }}\right)} \cdot \sigma \cdot \varepsilon_{\text {wall }}
\end{aligned}
$$

Transforming the equation (4) to $T_{\text {eq }}$ and apply the listed assumptions, the equivalent temperature can be solved as follows:

$T_{e q}=T_{a i r}+\frac{\alpha_{\text {rad }}}{\alpha_{c o m b}}$.

$$
\left(\left(T_{\text {atm }}-T_{\text {air }}\right) \cdot \varphi_{\text {atm }}+\left(T_{\text {earth }}-T_{\text {air }}\right) \cdot \varphi_{\text {earth }}\right)+\frac{q_{\text {short-wave }}}{\alpha_{\text {comb }}}
$$

\subsubsection{Modified equivalent air temperature based on VDI 6007}

Equation 6 implies a constant combined coefficient of heat transfer. As a further improvement, $\alpha_{\text {comb }}$ is computed as the sum of constant $\alpha_{\text {conv }}$ and a variable coefficient for long-wave radiation heat transfer $\alpha_{\text {rad }}$.

In addition, both $T_{\text {atm }}$ and $T_{\text {earth }}$ are computed by dividing them through the emissivity factor of the earth. According to $[16,17]$, it is more accurate to calculate the sky temperature with Equation $3 \mathrm{a}$. These changes from the originally VDI 6007-model are summarized under the variant name Mod VDI 6007.

\subsubsection{Combined outdoor temperature according to VDI 2078}

The revised German Guideline VDI 2078 describes cooling load calculations and provides a combined outdoor temperature. Formally, this temperature originates from a similar approach as the VDI 6007. However, the VDI 2078-model is further simplified by neglecting any changes in sky emissivity or in the coefficient of long-wave radiation heat exchange. Sky emissivity is set to 0.74 , which holds roughly 
true for summer [20]. Besides, the air temperature is taken as the direct reference temperature for all calculated heat fluxes. As this model represents a further simplification, we include it in our study and compare its results to the other three models.

$$
\begin{aligned}
& T_{\text {eq }}=T_{\text {air }}-\frac{\sigma \cdot \varepsilon_{\text {wall }}}{\alpha_{\text {comb }}} \cdot\left(\left(T_{\text {air }, m}\right)^{4}+\left(T_{\text {air }}-T_{\text {air }, m}\right) \cdot 1.05\right) \cdot \\
& \left(1-\varphi_{\text {atm }} \cdot \varepsilon_{\text {atm }}-\varphi_{\text {earth }} \cdot \varepsilon_{\text {earth }}\right)+\frac{q_{\text {short-wave }}}{\alpha_{\text {comb }}}
\end{aligned}
$$

\subsection{Indoor long-wave radiation exchange}

The long-wave radiation heat exchange within the building is commonly modelled in two different ways. One possibility, described in the VDI 6007 guideline, suggests calculating this way of heat exchange with a constant coefficient of heat transfer between inner and outer wall. The guideline prescribes a value of $5 \mathrm{~W} /\left(\mathrm{m}^{2} \mathrm{~K}\right)$, which can also be found in [21]. It holds true for non-metallic materials with an emissivity factor of 0.8 and a mean temperature of $26.85^{\circ} \mathrm{C}$. This method does not take into account the temperature dependency of longwave radiation heat exchange as formulated in the Stefan-Boltzmann law.

Alternatively, a heat balance between inner wall, outer wall, indoor radiation sources and transmitted solar radiation can be formed.

\section{Implementation}

For this study, we use the Modelica Standard Library and self-developed building model libraries. An overview of these libraries is given in $[6,22]$.

As all radiation heat exchange models described in Section 2 derive from a similar theoretical approach, we are able to define a partial model as a general base class (Figure 4).

$$
\begin{array}{|ll|}
\hline & \begin{array}{c}
\text { Equivalent air } \\
\text { temperature }
\end{array} \\
\hline+ & \mathrm{I}_{\text {Sol }} \\
+ & \mathrm{T}_{\text {air }} \\
\# & \mathrm{E}_{\text {atm }} \\
\# & \mathrm{E}_{\text {earth }} \\
\# & \varepsilon_{\text {wall }} \\
\# & \alpha_{\text {abs }} \\
\hline
\end{array}
$$

Figure 4: UML diagram of equivalent air temperature base class

The four different long-wave radiation exchange models all extend from this base class. This gives us the advantage to define a replaceable block for longwave radiation heat transfer (1) connected to our building physics model (2) which can then be set to use one of the four radiation models (Figure 5). The building model is connected via heat ports to the long-wave radiation heat transfer (a). Both are connected with a weather model, which provides solar radiation (b), outdoor air temperature, sky and terrestrial long-wave radiation (c). Furthermore, the building model needs additional information about infiltration rates (d), as well as about convective (e) and radiative ( $f$ ) inner loads via heat ports.

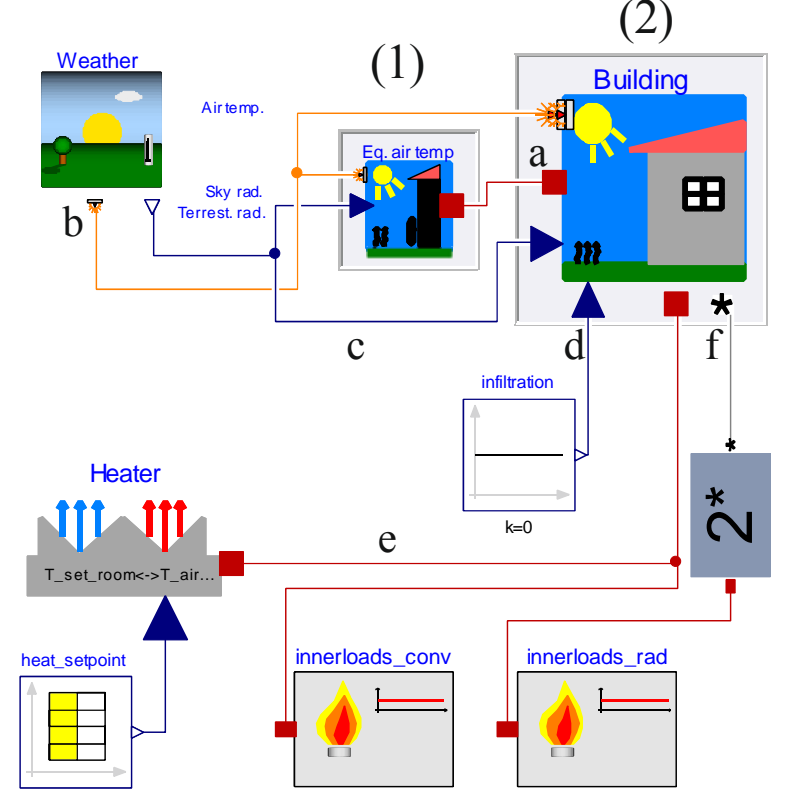

Figure 5: Implementation in Dymola

Taking advantage of separated definitions of convective and radiative heat transfer (see Section 1 ), we can easily change the definition of long-wave radiation heat exchange (see Figure 6).

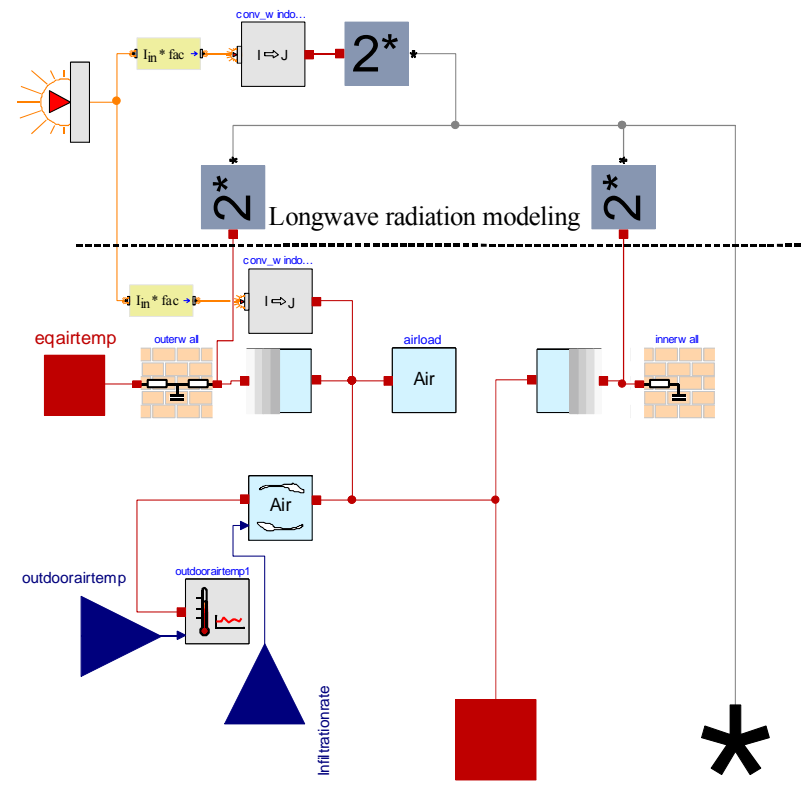

Figure 6: Zone model in Dymola

In the context of city district simulations, the objectoriented approach of Modelica is an important 
advantage. It allows a fast and easy use of the same model in several instances while adapting the submodels to the requirements of each instance.

A further advantage besides variable time step and object-orientation supported by Modelica in this context is acausal modelling. Energy supply systems at urban scale are relatively complex and flow directions for energy and mass flows are usually unknown.

\section{$4 \quad$ Test case and results}

\subsection{Test case}

To figure out the differences between the models and identify the most promising approach for our building model, we developed three test cases. Test Case 1 and Test Case 2 are based on the "Case 220: In-Depth Series Base Case" from ASHRAE 140. As most ASHRAE 140 in-depth tests, it is based on a single room consisting of five light-weight outer walls only. We simulated $1^{\text {st }}$ July of the typical meteorological year (TMY) provided with the standard [12]. Before and after the simulated day all initial temperatures are held constant. For Test Case 1 the outside wall is only subject to outdoor air temperature and long-wave radiation. Convection and absorption of short-wave radiation are not considered. Thus Test Case 1 uses outdoor air temperature and long-wave radiation from the atmosphere and the earth as input-data. Test Case 2 differs in the number of heat transfer mechanisms which affect the building envelope. Convection and absorption of short-wave radiation are additionally taken into account. Further inputs are thus solar radiation on tilted surfaces and combined as well as convective coefficients of heat transfer (set to 28.5 $\mathrm{W} /\left(\mathrm{m}^{2} \mathrm{~K}\right)$ and $24.67 \mathrm{~W} /\left(\mathrm{m}^{2} \mathrm{~K}\right)$ for walls, and 16.37 $\mathrm{W} /\left(\mathrm{m}^{2} \mathrm{~K}\right)$ for windows respectively). Only one day is simulated as well, all temperatures are held constant before and after that day. Other parameters of Test Cases 1 and 2 are listed in Table 1.

Table 1: Boundary conditions of Test Case 1 and 2

\begin{tabular}{|l|l|}
\hline \multicolumn{1}{|c|}{ PARAMETER } & \multicolumn{1}{c|}{ VALUE } \\
\hline Infiltration & $0 \mathrm{~m}^{3} / \mathrm{h}=$ const. \\
\hline Internal gains & $0 \mathrm{~W}=$ const. \\
\hline $\begin{array}{l}\text { Temperature of floor } \\
\text { coupling }\end{array}$ & $\mathrm{T}_{\text {air }}$ \\
\hline$\alpha_{\text {abs }}$ & 0.6 \\
\hline$\varepsilon_{\text {wall }}$ & 0.90 \\
\hline mech. equipment & none \\
\hline
\end{tabular}

The purpose of Test Case 3 is to emphasize on the inside long-wave radiation heat exchange, heat demand and simulation time. Since the simplified building model represents all outer and inner walls by one capacitance per class (see Section 2.1), radiation exchange can only occur if elements of both classes exist. We thus set up a test case with outer as well as inner walls. Test Case 3 is based on a two storey single-family dwelling with a living area of $150 \mathrm{~m}^{2}$. The building has a high thermal mass and is well insulated according to German Energy Savings Ordinance 2009. A full year is simulated. Calculation of the equivalent air temperature is performed with convective and long-wave radiation heat transfer as well as short-wave absorption. Combined and convective coefficients of heat transfer are set to $25 \mathrm{~W} /\left(\mathrm{m}^{2} \mathrm{~K}\right)$ and $20 \mathrm{~W} /\left(\mathrm{m}^{2} \mathrm{~K}\right)$ respectively. The boundary conditions for this case can be found in Table 2 .

Table 2: Boundary conditions of Test Case 3

\begin{tabular}{|l|l|}
\hline \multicolumn{1}{|c|}{ PARAMETER } & \multicolumn{1}{c|}{ VALUE } \\
\hline Infiltration & $0 \mathrm{~m}^{3} / \mathrm{h}=$ const. \\
\hline Internal gains & $0 \mathrm{~W}=$ const. \\
\hline $\begin{array}{l}\text { Temperature of floor } \\
\text { coupling }\end{array}$ & $10.36^{\circ} \mathrm{C}=$ const. \\
\hline$\alpha_{\text {abs }}$ & 0.38 \\
\hline$\varepsilon_{\text {wall }}$ & 0.90 \\
\hline mech. equipment & ideal heater \\
\hline Thermostat strategy & $22^{\circ} \mathrm{C}(6 \mathrm{~h}-20 \mathrm{~h})$ \\
& $17^{\circ} \mathrm{C}(20 \mathrm{~h}-6 \mathrm{~h})$ \\
\hline
\end{tabular}

All simulations are performed on a computer with following technical data (see Table 3).

Table 3: Data of used equipment

\begin{tabular}{|l|l|}
\hline \multicolumn{1}{|c|}{ CHARACTERISTIC } & \multicolumn{1}{c|}{ VALUE } \\
\hline Operating system & Windows 7 \\
\hline Number of processors & 4 \\
\hline Clock speed & $2.67 \mathrm{GHz}$ \\
\hline Working memory & $4 \mathrm{~GB}$ \\
\hline
\end{tabular}

To quantify differences between the models, a rootmean-square deviation (RMSD) is used. When comparing more than two models it is appropriate to form the RMSD between the minimum and the maximum of each hour. In this way a range within which the temperatures lie is calculated (RMSD-R).

\subsection{Limitations}

The major limitations in the presented work are:

- Subject of this analysis are only single-zone buildings with specific characteristics

- All models are based on assumptions; the results are compared between each other but not to measurements. 
- Empirical equations are used to calculate long-wave radiation as a function of outdoor air temperature. Thus, all models are dependent either directly or indirectly on outdoor air temperature.

- Heat balances for the models relate to slightly different locations (wall surface or nearby the surface) and cannot be harmonized.

- Convective heat transfer $\alpha_{\text {conv }}$ is regarded constant. In reality, it may vary over time depending on wind speed and direction.

- Our presented analysis is limited to single days and overall yearly values.

\subsection{Outdoor long-wave radiation exchange}

To understand the differences between the models, we investigated the surface temperatures on the building envelope as direct model outputs. The results of Test Case 1 with long-wave radiation load can be obtained in Figure 7. While the temperature of the VDI 6007-model holds the highest values, the model of guideline VDI 2078 holds the lowest. The RMSD between these two models is $11.24 \mathrm{~K}$. The high temperatures of the VDI 6007-model close to the outdoor air temperature are striking. In other investigations a rise above the outdoor air temperature was detected, which contradicts observation [23]. The Mod VDI 6007-model has a clearly lower course and converges to the most detailed Heat Balance-model. It is apparent that Mod VDI 6007 differs the most at high temperatures from Heat Balance. The RMSD between these two models is $0.54 \mathrm{~K}$ in contrast to $2.56 \mathrm{~K}$ for VDI 6007 and Heat Balance.

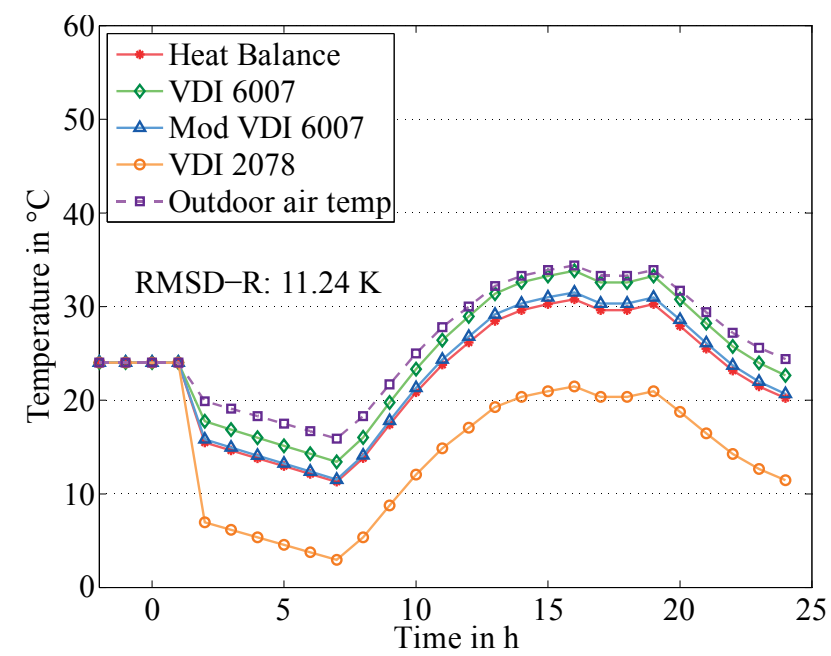

Figure 7: Equivalent outdoor temperature on July,1. of TMY; long-wave load

The comparably low temperatures of VDI 2078 can be explained by the handling of sky emissivity. The emissivity is assumed to be constant, which cannot be guaranteed for the investigated day. Sky conditions or reflection of long-wave radiation are not taken into account. Furthermore, the long-wave radiation heat transfer coefficient is not calculated dependent on ambient conditions.

Modifications in Mod VDI 6007 compared to VDI 6007 primarily concern long-wave radiation exchange. They cause a shift in the results towards the Heat Balance-model. Both models, Mod VDI 6007 and Heat Balance, calculate the sky temperature in the same way. Small differences at high temperatures can be justified as the Mod VDI 6007-model does not take a temperature depending emission of the wall into account.

Test Case 2 is a more realistic test case as it takes convection and short-wave radiation into account (see Figure 8). The aim is to analyse the impact of long-wave radiation under real conditions. As expected, the differences between the models decrease due to the new influences. Mainly responsible for this is convective heat transfer. This heat flux is calculated with a constant coefficient of $24.67 \mathrm{~W} /\left(\mathrm{m}^{2} \mathrm{~K}\right)$ for walls and $16.37 \mathrm{~W} /\left(\mathrm{m}^{2} \mathrm{~K}\right)$ for windows in all models, hence it is about 3-6 times higher than radiative heat transfer. However, the VDI 6007 and the VDI 2078 still represent the extremes. The RMSD between these two models decreases to $2.22 \mathrm{~K}$. Especially the extreme rise of VDI 2078 in contrast to the first test case is striking. The difference in the temperature after $24 \mathrm{~h}$ amounts to over $10 \mathrm{~K}$. On the one hand this shows the overestimation of long-wave radiation heat transfer of VDI 2078. On the other hand it displays the effect of convective heat transfer. Comparing Mod VDI 6007 and the Heat Balance, a difference is hardly recognizable (RMSD: $0.1 \mathrm{~K}$ ). All adapted temperatures rise over the ambient air temperature during the day, resulting from the short-wave radiation absorption.

Regarding the given test cases, the results justify the implemented simplifications in the VDI 6007 and Mod VDI 6007-models. Only the VDI 2078 shows major differences to the most complex Heat Balancemodel.

As expected, the convective heat transfer smoothes the equivalent temperatures of all models in Test Case 2. 


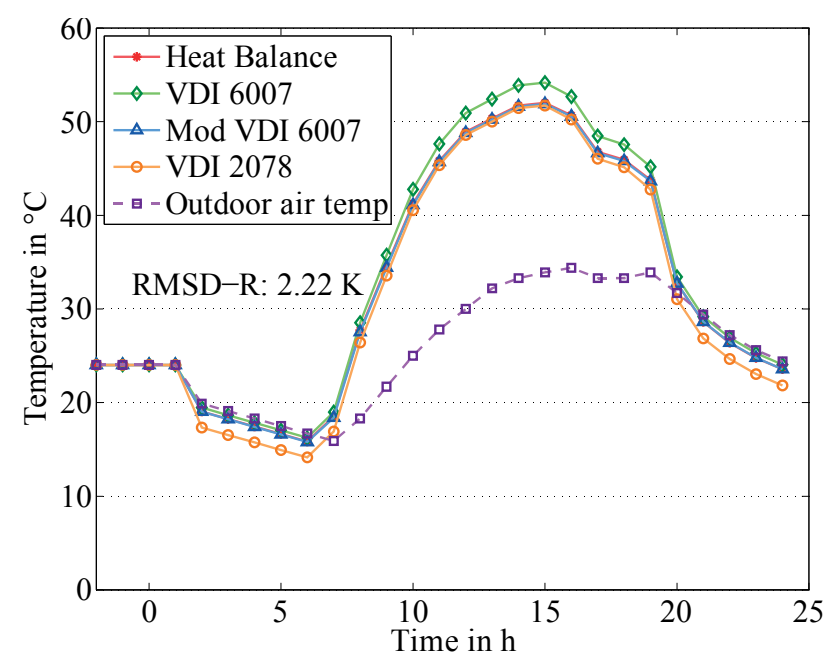

Figure 8: Equivalent outdoor temperature on July 1 of TMY; long-wave, short-wave and convective load

An overestimation of long-wave radiation heat exchange of VDI 2078 can be clearly observed. The rise over air temperature during the day in all models is caused by short-wave radiation absorption of the wall. In both test cases the strong dependency on the air temperature can be monitored.

In conclusion the Mod VDI 6007 model keeps the best accuracy compared to the complex Heat Balance-model while including important simplifications that lead to shorter computing times (see Figure 9).

\subsection{Indoor long-wave radiation exchange}

Besides the outdoor long-wave radiation heat exchange, different options exist to model indoor radiation exchange. In our analysis, we focus on heat demand and simulation time.

Figure 9 shows the CPU-time for a one-year simulation of Test Case 3. We simulated each equivalent temperature model with both explicit heat balance following the Stefan-Boltzmann law and a linearized approach. The CPU-time decreases using the linearized approach for indoor radiation. The percentages of savings in simulation time for simplified outdoor models are particularly remarkable. For the VDI 6007-model the simulation time is $52.16 \%$ shorter compared to the detailed indoor heat balance. The differences in simulation time result from the removal of the heat balances calculated with the Stefan-Boltzmann law. These heat balances contain a dependency on $\mathrm{T}^{4}$, which is solved iteratively. This is also the reason for the massive increase of needed time using Heat Balancemodel for the outdoor heat exchange.

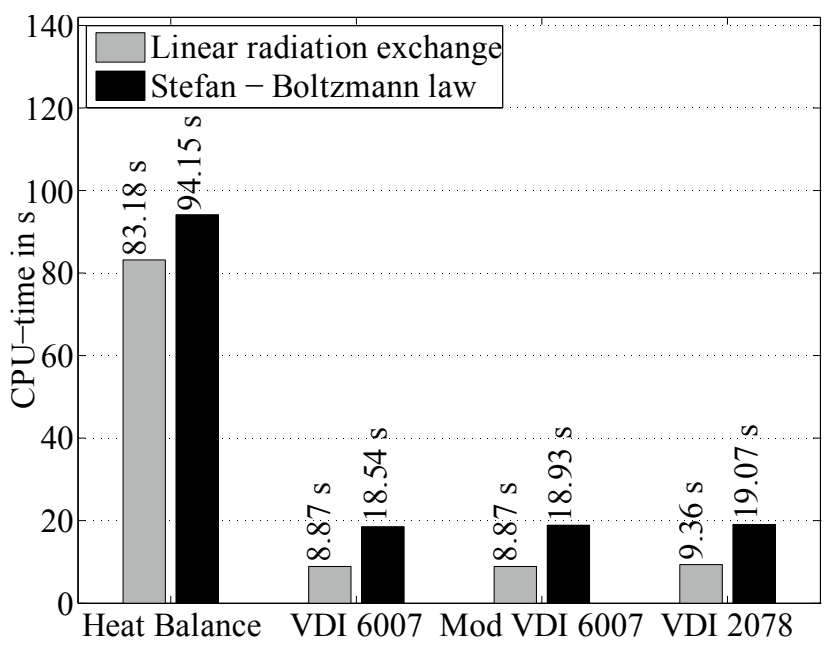

Figure 9: Comparison of linear radiation model and StefanBoltzmann law for indoor radiation exchange

As we control the indoor temperatures on a level between $17^{\circ} \mathrm{C}$ and $22^{\circ} \mathrm{C}$, the chosen coefficient of radiative heat transfer is justified (see Section 2.3). Hence, the different modelling approaches lead to no major differences in the simulated heat demand. Comparing the indoor models to each other the deviation over one year is below $2.1 \%$. This suggests using a linear approach for indoor radiation when keeping the indoor temperature on a controlled level is a valid simplification. Nevertheless, it is important to choose a corresponding coefficient of radiative heat transfer.

\section{Conclusion}

There are different options for modelling the indoor and outdoor long-wave radiation exchange in thermal building models for simulations at urbanscale. For improving these building models, a good trade-off between accuracy and simulation time is a major challenge. The main differences of common radiation modelling assumptions concern the impact of outdoor radiation sources and linearizing the Stefan-Boltzmann law.

To evaluate different radiation models for thermal network building models, we compared four adapted outdoor air temperature models. In addition, we investigated the handling of indoor radiation exchange with the Stefan-Boltzmann law and a linear approach.

For the comparison, we set-up three test cases on a generic room and a single family dwelling and analysed surface temperatures, heat demands and simulation times. We varied the number of radiation sources between the test cases to observe radiation heat exchange under generic and real conditions. 
Modelica proved to be a promising modelling language for urban-scale building simulations. We identified three major prerequisites and advantages:

- Allowing solvers with variable time steps

- Use of object-oriented modelling approaches

- Use of acausal modelling approaches

The results of the test cases show promising potential for an outdoor radiation exchange model based on a modified approach from German guideline VDI 6007. It includes important simplifications that lead to short computing time while keeping a sufficient accuracy. For indoor radiation exchange modelling at constant temperatures, a linear approach significantly reduces simulation time without major losses in accuracy. An additional comparison with measurement data could further help to validate this suggested approach.

\section{Acknowledgements}

We gratefully acknowledge the financial support for this project by BMWi (German Federal Ministry of Economics and Technology) under promotional reference 03ET1004A.

\section{Nomenclature}

$\begin{array}{lll}\mathrm{a}_{\mathrm{abs}} & \begin{array}{l}\text { coefficient of short- } \\ \text { wave absorption }\end{array} & \mathrm{W} /\left(\mathrm{m}^{2} \mathrm{~K}\right) \\ \alpha & \begin{array}{l}\text { coefficient of heat } \\ \text { transfer }\end{array} & \mathrm{W} /\left(\mathrm{m}^{2} \mathrm{~K}\right) \\ \mathrm{E} & \begin{array}{l}\text { long-wave radiation } \\ \text { emissivity factor }\end{array} & \mathrm{W} / \mathrm{m}^{2} \\ \mathrm{I}_{\text {sol }} & \text { solar radiation on } & \mathrm{W} / \mathrm{m}^{2} \\ & \text { tilted surface } & \\ \sigma & \begin{array}{l}\text { Stefan-Boltzmann- } \\ \mathrm{T}\end{array} & \mathrm{W} /\left(\mathrm{m}^{2} \mathrm{~K}^{4}\right) \\ \mathrm{q} & \text { Factor } \\ \varphi & \text { temperature } & \mathrm{K} \\ & \text { heat flux of wall } & \mathrm{W} / \mathrm{m}^{2} \\ & \text { view factor of long- } & - \\ \text { wave radiation source } & \\ \text { air } & \text { outdoor air } \\ \text { amb } & \text { ambient source } \\ \text { atm } & \text { extraterrestrial source } \\ \text { cond } & \text { conduction } & \\ \text { comb } & \text { convection } & \\ & \text { combined }\end{array}$

$\begin{array}{ll}\text { earth } & \text { terrestrial source } \\ \text { eq } & \text { equivalent } \\ \mathrm{m} & \text { daily average } \\ \mathrm{rad} & \text { long-wave radiation }\end{array}$

\section{References}

[1] Hensen J, Lamberts R. Building performance simulation for design and operation. Abingdon, Oxon, New York, NY: Spon Press; 2011.

[2] Clarke JA. Energy simulation in building design. 2nd ed. Oxford: Butterworth-Heinemann; 2001.

[3] Robinson D (ed.). Computer modelling for sustainable urban design: Physical principles, methods and applications. 1st ed. London: Earthscan; 2011.

[4] Kämpf JH, Robinson D. A simplified thermal model to support analysis of urban resource flows. Energy and Buildings 2007;39(4):445-53.

[5] Wetter M, van Treek C. IEA EBC Annex 60. [November 15, 2013]; Available from: http://www.iea-annex60.org/.

[6] Müller D, Hosseini Badakhshani A. Gekoppelte Gebäude- und Anlagensimulation. In:

Proceedings BauSim Conference; 2010.

[7] Nytsch-Geusen C, Huber J, Ljubijankic M, Rädler J. Modelica Buildingsystems - eine Modellbibliothek zur Simulation komplexer energietechnischer Gebäudesysteme. In: Proceedings BauSim Conference 2012; 2012, p. 271-278.

[8] Wetter M, Zuo W, Nouidui TS. Recent Developments of the Modelica "Buildings" Library for Building Energy and Control Systems. In: Proceedings 8th Modelica Conference; 2011, p. 266-275.

[9] Bonvini M, Leva A. Exploiting Object-Oriented Modelling for Scalable-Detail Studies on Control for Energy Efficiency. In: Proceedings 2012 IEEE Multi-conference on Systems and Control; 2012, p. 770-775.

[10] German Association of Engineers. Calculation of transient thermal response of rooms and buildings - Modelling of rooms;91.140.10(VDI 6007-1). Düsseldorf: Beuth Verlag GmbH; 2012.

[11] Lauster M, Teichmann J, Fuchs M, Streblow R, Mueller D. Low order thermal network models for dynamic simulations of buildings on city district scale. Building and Environment 2014;73:223-31. 
[12] American Society of Heating, Refrigerating and Air-Conditioning Engineers. Standard Method of Test for the Evaluation of Building Energy Analysis Computer Programs(ASHRAE 140-2007). Atlanta: ANSI/ASHRAE; 2007.

[13] Shi Z, Zhang X. Analyzing the effect of the longwave emissivity and solar reflectance of building envelopes on energy-saving in buildings in various climates. Solar Energy 2011;85(1):2837.

[14] German Association of Engineers. Environmental Meteorology;13.040.10(VDI 3789-2). Düsseldorf: Beuth Verlag GmbH; 1994.

[15] Christoffer T, Deutschländer M., Webs M. Testreferenzjahre von Deutschland für mittlere und extreme Witterungsverhältnisse TRY. Deutscher Wetterdienst, Offenbach 2004.

[16] EnergyPlus Development Team. EnergyPlus Engineering Documentation. [November 15, 2013].

[17] Müller E. Development of a test reference year on a limited data base for simulations on passive heating and cooling in Chile. In: Proceedings Building Simulation Conference; 2001.

[18] Nehring G. Über den Wärmefluß durch Außenwände und Dächer in klimatisierten Räumen infolge der periodischen Tagesgänge der bestimmenden meteorologischen Elemente. Gesundheits Ingenieur 1962;83(7):185-216.

[19] Mackey CO, Wright LT, Ithaca NY. Periodic heat flow - homogeneous walls or roofs. Transactions American Society of Heating and Ventilating Engineers 1944(50):293-312.

[20] German Association of Engineers. Cooling Load Calculation of Air-conditioned Rooms;91.140.30(VDI 2078-1). Düsseldorf: Beuth Verlag GmbH; 1996.

[21] German Association of Engineers. VDI heat atlas. 2nd ed. Heidelberg: Springer; 2010.

[22] Lauster M, Streblow R, Müller D. ModelicaBibliothek und Gebäudemodelle. In: Proceedings Symposium Integrale Planung und Simulation in Bauphysik und Gebäudetechnik: 26.03. 28.03.2012, Technische Universität Dresden; 2012.

[23] Norbert Nadler. Validierung des Rechenkerns der C.A.T.S.-Kühllastberechnung anhand der neuen VDI 6007-1. HLH Lüftung/Klima Heizung/Sanitär - Gebäudetechnik 2013;64(1):36-41. 